\title{
Centro Histórico de Rio Pardo: lembranças esquecidas ou esquecidas lembranças?
}

\author{
Historic District of Rio Pardo: forgotten memories or memories forgotten?
}

\section{Heloisa Helena Fernandes Gonçalves da Costa}

Universidade Federal da Bahia - UFBA - Salvador - Salvador - Brasil

\section{Eduardo Alexandre Louzado}

Universidade Federal de Santa Maria - UFSM - Santa Maria - Rio Grande do Sul - Brasil

\begin{abstract}
Resumo: A cidade de Rio Pardo / RS / Brasil mantém até hoje, diversos e significativos registros materiais do passado que, muito mais que simples edificações - sobreviventes ao impetuoso tempo, são marcos que contemporanizam informações, regem relações sociais e (re)escrevem a história e a identidade local. E, portanto, busca-se (re)discutir, partindo da constatação e representação da mídia impressa regional, se os 200 anos da cidade de Rio Pardo e seus imóveis considerados como monumentos, estão impactando autoridades e população ao ponto do desejo de salvaguardá-los. Recorrendo-se para tanto, as constatações da mídia, encontrou-se, referenciados ao patrimônio cultural material da cidade de Rio Pardo, uma dicotomia de ações que por hora referenciam um processo dialógico entre os diversos atores sociais do município/região/estado que, em consonância buscam a salvaguarda e preservação deste, por hora denuncia o total descaso e negligência com a referida proteção.
\end{abstract}

Palavras-chave: Centro Histórico. Rio Pardo. Patrimônio Cultural.

\begin{abstract}
The city of Rio Pardo / RS / Brazil holds today, diverse and significant property records of the past, much more than just buildings - survivors to the impetuous time, are milestones that contemporanizam information, govern social relations and (re) write history and local identity. And therefore, we try to (re) discuss, based on the observation and representation of regional print media, is the 200th anniversary of the city of Rio Pardo and its properties considered as monuments, they are impacting authorities and population to the point of desire safeguarded them. By employing for both the media findings, met, referred to cultural heritage material from the city of Rio Pardo, a dichotomy of actions per hour reference a dialogical process between the various stakeholders of the municipality / region / state, in line seek the protection and preservation of this for now denounces the total disregard and neglect with that protection.
\end{abstract}

Keywords: Historic District. Rio Pardo. Culture Heritage. 


\section{1 "Cada tempo em seu lugar"}

Intrinsecamente ligada à história da IberoAmérica, a jovem mas porém bicentenária cidade de Rio Pardo / RS / Brasil mantém até hoje, diversos e significativos registros materiais do passado que, muito mais que simples edificações - sobreviventes ao impetuoso tempo, são marcos que contemporanizam informações, regem relações sociais e (re)escrevem a história e a identidade local, como canta Gilberto Gil: "cada tempo em seu lugar / preciso refrear um pouco o meu desejo de ajudar / não vou mudar um mundo louco dando socos para o ar / não posso me esquecer que a pressa / é inimiga da perfeição / se eu ando o tempo todo a jato, ao menos / aprendi a ser o último a sair do avião “".

Este expressivo e simbólico conjunto de edificações dispostas, principalmente, na área central da cidade - é suporte de lembranças do período colonial e da açorianidade $^{2}$ riopardense, como descreve Costa (2006, p.5) "a área central de Rio Pardo, [...] denominada Centro Histórico, mantém grande parte das características originais do período colonial, com prédios que sofreram poucas descaracterizações."

O denominado Centro Histórico que, pela Lei Estadual no 12.003, de 21 de outubro de 2003 foi declarado integrante do Patrimônio Cultural do Estado do Rio Grande do Sul é delimitado, conforme seu art. $2^{\circ}$, por:

“I - a oeste, pela rua Dr. Luciano Raul Panatieri; II - a noroeste, pela rua 15 de novembro; III - a leste, pela rua Dr. João Pessoa;

IV - a nordeste, pela rua Senhor dos Passos; V - a norte, pela rua Andrade Neves; VI - a leste, mais uma vez, pela rua Gomes Freire de Andrade; VII - a sudeste, pela rua José Feliciano de Paula Ribas; VIII - a sudeste, mais uma vez, pela rua General Godolfin; IX a leste, mais uma vez, pela rua Rafael Rodrigues Pinto Bandeira; X - a sul, pela rua Francisco Alves; XI - a noroeste, mais uma

\footnotetext{
${ }^{1}$ Gilberto Passos Gil Moreira (Salvador, 26 de junho de 1942), mundialmente conhecido como Gilberto Gil, é um político, cantor, compositor, multi-instrumentalista, escritor, ambientalista, empresário e intelectual brasileiro que foi Embaixador da ONU para agricultura e alimentação e exMinistro da Cultura do Brasil. Conhecido por sua inovação musical, com a música "Cada tempo em seu lugar", gravada em 1989, discute a ideia da indissociabilidade do tempo-espaço.

${ }^{2} \mathrm{O}$ termo é utilizado para designar identidade cultural açoriana.
}

vez, pela rua Coronel Franco Ferreira; XII - a sudeste, mais uma vez, pela rua General Câmara; XIII - a oeste, mais uma vez, pela rua Moinhos de Vento; XIV - a oeste, mais uma vez, pela rua Ernesto Alves."

A referida poligonal que delimita esta área histórica (Figura 1), apenas não abarca sete das 35 edificações que constam na relação dos bens considerados de valor histórico e cultural da cidade de Rio Pardo integrantes do Plano Diretor (Figura 2), conforme texto da Lei Municipal nำ 08 de 27 de abril de 1979, o que por sua vez, tem feito com que este denominado Centro Histórico, tenha sido pauta de constante discussões e (re)pensares, uma vez que como apresenta Dias (2009, p.22) “a proteção do patrimônio cultural edificado na cidade [...] é uma forma de garantir a cidadania cultural à coletividade, protegendo o direito fundamental à preservação da memória e da identidade", considerando que a lembrança o é, em larga medida, uma (re)construção do passado com a ajuda de dados emprestados do presente, e além disso, preparada e estruturada em outras reconstruções feitas em anteriores períodos e de onde a imagem de outrora se manifestou já bem alterada. (HALBWACHS apud Costa, Remedi, 2013, p.34)

Figura 1- Mapa com demarcação do Centro Histórico de Rio Pardo, considerando a Lei 12.003/2003.

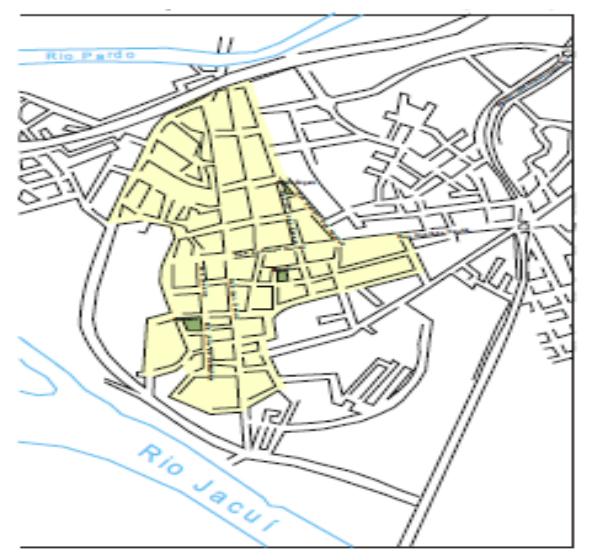

Fonte: Costa (2006, p. 88) 
Figura 2- Mapa com a localização dos prédios arrolados conforme Plano Diretor de Rio Pardo que estão inseridos no Centro Histórico.

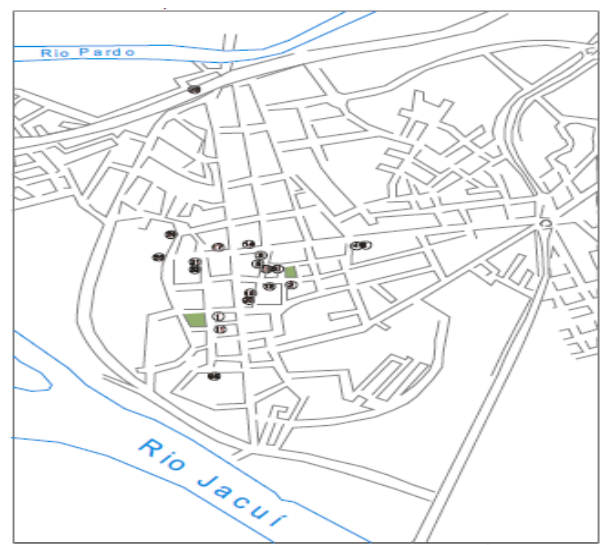

Fonte: Costa (2006, p. 79)

Ao reforçar-se que segundo Garcia (2011, p. 49) Rio Pardo é "possuidor de vasto patrimônio arquitetônico, juntamente com os demais legados portugueses e sua área histórica do município é considerada Patrimônio Cultural do Rio Grande do Sul" se acresce a relevância de que, conforme inventário do IPHAE ${ }^{3}$ se encontra neste Centro

Histórico, a Rua da Ladeira ${ }^{4}$, tombada em nível nacional.

A luz destas considerações, sobre a área histórica do município, a arquiteta e urbanista Adriana Costa pontua

"a cidade de Rio Pardo possuí duas características muito peculiares: em primeiro lugar, a variabilidade de tipologias arquitetônicas, composta por edificações que datam desde a segunda metade do século XVIII, tais como a Igreja Matriz, a Capela São Francisco de Assis e o Solar do Almirante Alexandrino e edificações da década de 1950, como o atual prédio da Prefeitura Municipal, em estilo modernista." (COSTA, 2006, p.92)

\footnotetext{
${ }^{3}$ O Instituto do Patrimônio Histórico e Artístico do Estado do RS (IPHAE) é o órgão no estado do Rio Grande do Sul responsável preservação dos bens considerados de relevância histórica e/ou artística.

${ }^{4}$ Atual Rua Júlio de Castilhos, foi a primeira rua calçada no Rio Grande do Sul, no ano de 1813. Utilizando o trabalho escravo, segue o modelo da Via Appia Romana, com escoamento no centro do calçamento. Por ter sido a 1ำ rua calçada, se conserva o estilo original. Foi tombada pelo Patrimônio Histórico e Artístico Nacional em 1954. Disponível em: <http://www.riopardo.rs.gov.br/site/turismo/visualizar/id/8/?Ruada-Ladeira.html> Acesso em: 02 de agosto 2015.
}

Esta observação postulada confere ao espaço urbano e referido Centro Histórico riopardense através da coexistência de edificações de diferentes períodos, um caráter bastante diversificado em particular, e, para tanto, independente do simbolismo e/ou origem do valor, a organização e a preservação destes busca, ao longo dos tempos, a perpetuação não somente do objeto material, mas também o suporte de memórias de um grupo ou de uma sociedade. (LOUZADO; COSTA, 2015, p. 172)

Ao considerar-se desta forma, a relevância da salvaguarda dos imóveis considerados patrimônios, Costa (2012, p.92) questiona: "onde se encontra a alma da cidade, aquela espécie de memória que não deveria desaparecer e pela qual vale a pena criar instrumentos de tombamento? Como proteger tantos tipos diferentes de patrimônios?"

E, portanto, ao refutar-se uma preocupação patrimonial no sentido da proteção de um passado clássico e monumental, mas sim, em consonância a dinâmica da vida onde, segundo Chagas (2002, p. 74), "o interesse no patrimônio não se justifica pelo vínculo com o passado seja ele qual for, mas sim pela sua conexão com os problemas fragmentados da atualidade, a vida dos seres humanos em relação com outros seres, coisas, palavras e ideias", busca-se (re)discutir, partindo da constatação e representação da mídia impressa regional ${ }^{5}$, se os 200 anos da cidade de Rio Pardo e seus imóveis considerados como monumentos, estão impactando autoridades e população ao ponto do desejo de salvaguardá-los.

\section{A Tranqueira Invicta de Rio Pardo - origem, ascensão e declínio Aspectos da dinâmica recente dos mercados de trabalho no Brasil}

A origem de Rio Pardo está vinculada diretamente aos interesses portugueses no processo

\footnotetext{
5 Corroboram para estas reflexões as constatações e representações que a mídia impressa regional - Jornal Gazeta do Sul, tem publicado acerca do patrimônio cultural material de Rio Pardo. Como recorte temporal, foram analisados os exemplares diários, de 07 de outubro de 2009 à 31 de maio de 2015, compreendendo 1589 edições. Este período, base da análise, compreende todas as publicações subseqüentes as comemorações do bicentenário da cidade, em 07/10/2009 até a data de finalização deste.
} 
expansionista, sobreposto que em 1750, com o Tratado de Madri estabeleceram que Portugal anexasse - em troca da Colônia de Sacramento que seria destinada a Espanha - as Missões.

Para a demarcação dos limites fronteiriços, conforme Vogt et al (1996, p.55) "em meados de 1751, o Capitão-General Gomes Freire de Andrade determinou que, na margem esquerda da confluência dos rios Pardo e Jacuí, no local hoje denominado Alto da Fortaleza, fosse criado um depósito de víveres e munição."

Frente aos interesses lusos e a função estratégica para a defesa destes, no ano seguinte a criação do depósito de víveres e munição no Alto da Fortaleza em 1752, iniciaram a construção de uma fortaleza, como descreve Costa (2006, p.68) "a Fortaleza Jesus-Maria-José, um dos elementos que deram origem ao traçado da cidade,[...] foi implantada com o objetivo de consolidar o processo de ocupação do território do Rio Grande do Sul, no sentido de proteção das divisas."

Com o freqüente e crescente número de conflitos na região, a população civil - formada principalmente por tropeiros, comerciantes e açorianos, a procura de segurança, começou a aproximar-se da fortificação, despontando e originando desta forma, a cidade de Rio Pardo.

Em 1763, as já conquistadas terras gaúchas, pelos portugueses, tentaram ser reconquistadas pelos espanhóis que, tomaram a colônia portuguesa - no Uruguai, do Santíssimo Sacramento, conquistaram Rio Grande e, almejando conquistar toda a Capitania de São Pedro, investiram contra Rio Pardo. Sem lograr êxito e conquistar o Forte Jesus-Maria-José, os espanhóis tiveram que recuar. Segundo Vogt et al (1996, p.56) "embora sofresse diversos ataques, a Fortaleza Jesus-Maria-José transformou-se num obstáculo intransponível para as milícias platinas que não a conseguiram tomar, razão pela qual passou a ser orgulhosamente chamada de "Tranqueira Invicta" pelos partidários da causa portuguesa."

Em 1769 o povoado então estabelecido foi elevado à condição de freguesia de Nossa Senhora do Rosário.
O governo português, com suas conquistas consolidadas, promove em 1809 a primeira divisão administrativa do Rio Grande do Sul, com a criação das quatro primeiras vilas: Porto Alegre, Rio Pardo, Rio Grande e Santo Antônio da Patrulha. Rio Pardo, com uma área de $156.803 \mathrm{~km}^{2}$, e a maior delas, foi elevada à categoria de sede municipal, em virtude do seu elevado progresso material alcançado. (VOGT et al, 1996)

A Vila de Rio Pardo era próspera, devido à produção da pecuária e ao comércio, fartamente desenvolvidos em virtude de sua localização, às margens do rio Pardo.

"Neste período, a cidade era importante entreposto comercial, uma vez que, com sua posição estratégica, junto ao rio, favorecia o transporte de mercadorias que vinham de Porto Alegre e que seguiam via estradas de chão para o interior do estado, mais especificamente, para a região das Missões Jesuíticas. Assim, nesta época, Rio Pardo era tão ou mais importante que a capital do estado, tendo, durante algum tempo, população superior à de Porto Alegre, predominante de índios, escravos e portugueses." (COSTA, 2006, p. 68)

Aos poucos, a zona urbana foi recebendo melhoramentos: agências de correios, calçamento de ruas e, como apresenta Lopes (2014, p. 71) "Rio Pardo foi uma das três povoações do Rio Grande do Sul contemplada com uma escola no início do século XIX".

O desenvolvimento e a prosperidade da cidade também foram registrados pelo naturalista francês Auguste de Saint-Hilare, durante sua passagem pela Vila de Rio Pardo em 18 de maio de 1821. No seu diário consta que a rua principal da cidade é parcialmente pavimentada, enquanto que a maioria das casas são telhadas - sendo algumas grandes e bem construídas; se visualiza, de forma abastada, grande número de casas com um ou dois andares, onde quase todas que denunciam certa riqueza, possuem sacadas envidraçadas. "É na rua principal que se vê a maior parte das lojas e armazéns de comestíveis, uns e outros igualmente bem sortidos. Embora Rio Pardo seja uma cidade rica e comercial, nenhuma providencia foi tomada até agora para 
facilitar o desembarque das mercadorias".(SAINTHILAIRE, 1987, p.363)

Este franco desenvolvimento colonial permitiu que, em 31 de março de 1846, a Vila fosse elevada a categoria de cidade.

Os resquícios deste exponencial desenvolvimento sobreviveram aos séculos:

"a cidade mantém várias características da época de sua formação, como o traçado original e expressivo número de edificações e símbolos representativos da história da cidade. Devido a estas características, configura-se atualmente como um pólo cultural e histórico, tanto do estado quanto da região do Vale do Rio Pardo, na qual encontra-se inserido." (COSTA, 2006, p. 14)

Entretanto, na atualidade, mesmo sendo um pólo cultural e histórico na região do Vale do Rio Pardo, o município de Rio Pardo não logrou satisfatório desenvolvimento e projeção econômica como outrora.

Já em 1858, o médico e naturalista alemão Robert Avé-Lallemant, durante sua passagem pelo então município de Rio Pardo, registrou que quanto ao desenvolvimento econômico desta cidade já se observava que enquanto uma ou outra das principais ruas exibiam quarteirões inteiros de casas e até magníficas residências, diversas travessas assentavam fileiras muito interrompidas de edifícios de muitas janelas e bastante compridos, e vazios. Esta observação foi complementada pelo registro de que "não mais funcionam as casas comerciais do andar térreo, a parte superior está desabitada; com as casas em ruínas, perde-se um bom capital”. (AVÉLALLEMANT, 1980, p. 167)

Partindo da premissa que até 1850, logo após sua elevação a categoria de cidade, Rio Pardo teve um ascendente ritmo de desenvolvimento, iniciando, lentamente, a declinar desde então, Rezende (1993, p. 88) "detecta este declínio econômico nos seguintes fatos: nos saques sofridos pelo comércio local durante a Revolução Farroupilha; na morte de grande número de rio-pardenses na Guerra do Paraguai e em virtude da epidemia de cólera-morbos que, em 1867, dizimou parte da população da cidade; entre outros”.

Quanto ao lento desenvolvimento econômico de Rio Pardo, Vogt et al (1996, p. 64) destacam que este baixo crescimento "a partir de meados do século XIX, está vinculado com a incapacidade que teve sua gente, fundamentalmente a sua classe dirigente, de aproveitar a acumulação de capitais proporcionado pela atividade comercial para desenvolver 0 artesanato, a manufatura e a indústria". Complementam os autores que esta elite política, "sobre cujos ombros pesava uma tradição e cultura de passado heróico, patrimonialista e escravocrata", não conseguiu conduzir a cidade à "modernidade industrial", levando a condenação da promissora e florescente tranqueira invicta à estagnação econômica. (VOGT et al, 1996, p.65)

\section{A açorianidade e o legado edificado}

O fluxo açorita e a contribuição açoriana ${ }^{6}$ no Rio Grande do Sul tem sido pauta de uma constante discussão acadêmica. Entre as contradições, como afirma Flores (2013, p. 59) "há historiadores que exageram a influência açoriana no Rio Grande do Sul, esquecendo-se que o fluxo açorita foi pequeno, de curta duração e que os casais eram pobres e sem maiores instruções, perdendo suas raízes ao longo dos 20 anos que viveram sem terras, à espera da migração para as Missões".

Outra importante constatação apresentada por Graebin (2007, p. 2) é "de como os municípios do Rio Grande do Sul buscam desenvolver o turismo cultural, evocando, a sua açorianidade" onde, em face a exploração turística, a influência açoriana é percebida nos "festivais de música, especialmente nas cidades do litoral norte, que tem origem açoriana, [...] na arquitetura das cidades onde sua presença foi marcante (Rio Pardo, Triunfo, Taquari, Santo

\footnotetext{
6 Adota-se por açoriano(a) o(a) habitante dos Açores, arquipélago constituído por 9 ilhas: Santa Maria, São Miguel, Terceira, Pico, Corvo, Flores, São Jorge e Faial, que começou a ser povoado, pela Coroa Portuguesa, a partir do século XV, que em primeiro momento, objetivava obter trigo para 0 abastecimento do reino, e por conseguinte, que os habitantes destas ilhas servissem de protetores e vigilantes do comércio marítimo português.
} 
Antônio), nos costumes, tradições, mitos, na religião (o culto do Espírito Santo)". (FRANZEN, 2003, p. 123)

Entretanto, no que tange à arquitetura - e em especial ao município de Rio Pardo, esclarece o professor Moacyr Flores que "o que se aponta como casas açorianas no interior de Santo Antônio, Porto Alegre, Viamão e Rio Pardo são, na verdade, casas de arquitetura popular portuguesa, existentes em Portugal e nos Açores." (VOGT; BERTÓ, 2010, p. 159)

Contudo, independente das discussões acerca da relevante exponencialidade - ou não, do fluxo migratório açoriano no estado, o Governo do Estado do Rio Grande do Sul em virtude da expressiva presença açoriana em seus patrimônios cultural material e imaterial, reconhece e contribui para a difusão cultural destes, através do Decreto ํㅜ 41.249, de 30 de novembro de 2001, que, em seu Artigo 1ํㅡ, preceitua:

"Fica consagrado o biênio 2001-2002 aos 250 anos do povoamento açoriano no Rio Grande do Sul, a fim de que nele sejam realizados os eventos comemorativos que celebram, dentre outros aspectos, a influência portuguesa na formação da cultura sul-riograndense e a contribuição daquele povo para a consolidação territorial, administrativa e política do Estado."

Corroborando com esse entendimento e o expressivo legado açorita, o município de Rio Pardo, de acordo com o texto da Lei Municipal nํㅜ 08 de 27 de abril de 1979, relaciona como sendo bens materiais de valor histórico e cultural da cidade, circunscritos no perímetro de seu Centro Histórico:

1) Igreja Matriz Nossa Senhora do Rosário;

2) Capela de São Francisco e respectiva estatuária;

3) Capela dos Passos;

4) Acervo do Museu de Arte Sacra;

5) Prédio onde funcionou a Escola Militar;

\footnotetext{
${ }^{7}$ Decreto Estadual / Rio Grande do Sul, no 41.249, de 30 de novembro de 2001. Disponível em: <http://www.al.rs.gov.br/legis/M010/M0100099.ASP?Hid_Tipo= TEXTO\&Hid_TodasNormas $=1323 \& \mathrm{hTexto}=\&$ Hid_IDNorma $=132$ 3> Acesso em: 02 de agosto 2015.
}

6) Prédio Sede do Clube Literário e Recreativo;

7) Prédio da Rua Júlio de Castilhos, de no 303;

8) Prédio onde funcionava o Instituto Medianeira;

9) Solar do Almirante Alexandrino de Alencar;

10) Fachada de Azulejos do prédio $\mathrm{n}^{\circ}$ 1028 da R. Almte Alexandrino de Alencar;

11) Casa de n 371 na Rua Júlio de Castilhos;

12) Prédio da Rua Andrade Neves, de $n^{\circ}$ 14 ;

13) Prédio da Rua Andrade Neves, de no 164;

14) Sobrado da Rua Dr. João Pessoa, de no 843;

15) Prédio da Rua Almirante Alexandrino de Alencar, de no 1087;

16) Prédio da Rua Almirante Alexandrino de Alencar, de no 1093;

17) Prédio da Rua Almirante Alexandrino de Alencar, de no 1113;

18) Prédio da Rua Andrade Neves, de $n^{\circ}$ 125;

19) Estação Ferroviária da Sede;

20) Antigo Cemitério Municipal;

21) Prédio da Rua Ernesto Alves, de $n^{\circ}$ 135;

22) Prédio da Rua Ernesto Alves, de $n^{\circ}$ 151 ;

23) Igreja São João;

24) Sobrado da Praça da Ponte;

25) Igreja Metodista;

26) Prédio da Casa do Turista;

27) Monumento do Barão de Santo Ângelo;

28) Prédio onde funcionou a $1^{\circ}$ U Usina Elétrica de Rio Pardo; 


\section{Os registros}

Ponto de partida desta análise, o dia 07 de outubro de 2009, data do bicentenário da assinatura do Decreto Real que elevou a localidade à categoria de Vila, foi amplamente divulgado pela edição diária do jornal que, entre tantos destaques, grifou as palavras do então prefeito municipal

"estamos trabalhando em prol do desenvolvimento de um município que guarda em si a história do povo gaúcho, suas origens e seus grandes feitos. Sejamos nós os novos personagens que farão parte das vitórias comemoradas nos próximos séculos. [...] Mas precisa manter viva em seus corações, pois muitos foram ao campo de batalha para que, hoje, o orgulho pulsasse em nossas veias pelo solo em que nascemos."

Fonte de destaque nesta mesma edição, foi o lançamento do livro "Uma luz para a história do Rio Grande: Rio Pardo 200 anos: cultura, arte e memória", organizado pelo historiador e professor Dr. Olgario Vogt que, em parceria com a $6^{\circ}$ Coordenadoria Regional de Educação, foi distribuído para todas as escolas da rede pública estadual do Vale do Rio Pardo. Entre os festejos populares, um desfile comemorativo no centro da cidade (com a presença de escolares e diversos organizações governamentais e não-governamentais) bem como os shows musicais de encerramento da festividade.

Consta registro também, que de forma solene, o poder legislativo municipal, realizou sessão especial alusiva ao bicentenário do município, agraciando com Medalhas Especiais, diversas personalidades que contribuem ou contribuíram com o desenvolvimento social-artístico-cultural do município.

Focando, uma presumível preocupação do poder público com a salvaguarda do patrimônio cultural material e preservação do Centro Histórico, também foram notícias em edições seqüentes:

- Uma reunião técnica, realizada no município, entre o prefeito municipal e o diretor do Iphae, onde o

\footnotetext{
8 Excerto do discurso do Sr Joni Lisboa da Rocha, prefeito municipal de Rio Pardo, publicado no Jornal Gazeta do Sul, no dia 07/10/2009, página 17, disponível em: $<$ http://www.grupogaz.com.br/gazetadosul/index/edicao:200910-07.html>
}

Instituto do Patrimônio Histórico e Artístico do Estado formalizou um termo de cooperação com o município, objetivando valorizar por meio do tombamento, igrejas, prédio e praças da cidade;

- A tentativa não concretizada do poder público de habilitar-se no Programa de Aceleração do Crescimento (PAC) das Cidades Históricas, criado pelo governo federal e executado desde 2009;

- A apresentação do projeto denominado "Rio Pardo no Futuro da História: plano de requalificação da área central", que objetivava fazer intervenções nas principais praças, ruas e estádio municipal, através de um plano de reestruturação da área urbana onde se localiza a maior parte do patrimônio histórico e arquitetônico da cidade;

- Uma reunião técnica entre prefeito, secretários municipais, arquitetos e engenheiros locais com o intuito de evitar a perda da herança cultural, difícil de ser mantida, ora por alterações grotescas na estrutura, ora pela ornamentação excessiva das fachadas dos prédios com placas e outdoors; e

- A assinatura da portaria de tombamento pelo Iphae da Igreja Matriz Nossa Senhora do Rosário, tornando o templo patrimônio de cultura do Estado, ficando resguardado também o seu entorno.

Entre as ações fomentadas pelo Ministério Público, foram destaque os TAC (Termo de compromisso de ajustamento de conduta) que almejam a recuperação e preservação dos prédios: Casa Borges, Sobrado Simões Pires, Sobrado Braun, prédio do Quinca da Botica, Igreja São Francisco, Casa dos Azulejos e Antigo Hotel Centenário.

A exposição das críticas situações e dos relevantes riscos e danos ao patrimônio foram recorrentes, em especial:

- a Matriz Nossa Senhora do Rosário, fechada desde 2008, devido à precariedade estrutural para receber o público;

- ao fechamento e precariedade do Solar do Almirante Alexandrino de Alencar e respectivo Museu Municipal Barão de Santo Ângelo que, conforme as palavras da coordenadora Ainda Ferreira "o prédio tem mais de 200 anos, sem manutenção não há 
como resistir, pois não foi feito para durar a vida inteira. Para complicar ainda mais, o imóvel está infestado de cupim e tomado por rachaduras. O museu precisa de restauro completo!"9;

- a interdição, pelo Corpo de Bombeiros do município, da rua onde se encontra o Solar dos Quadros - um dos prédios históricos mais antigos do município, que aparece na primeira planta da cidade, de 1829, que ameaça ruir, em virtude de apenas as paredes em ruínas ainda permanecem eregidas;

- a falta de reparos na estrutura sobre o rio Pardo, hoje chamada de Ponte Velha, no antigo caminho a Cachoeira do Sul, que começou a ser construída no começo do século XIX, entre 1816 e 1825;

- a necessidade de obras emergenciais a Igreja São Francisco de Assis, inaugurada em 1812, que em decorrência de estragos causados por goteiras e cupins, encontra-se com portas fechadas a qualquer cerimônia religiosa durante três anos;

- a interdição, pelo Corpo de Bombeiros, do Sobrado João Pereira Monteiro, com retirada de todos os inquilinos e lacramento de todas as dependências, em função de más condições de conservação e problemas estruturais;

- a tentativa de transferência para a iniciativa privada - pela prefeitura municipal, do prédio do Antigo Fórum, datado do início do século 19, que encontra-se em precárias condições estruturais e físicas, em avançado estado de deteriorização, sem ocupação a mais de duas décadas;

As práticas coletivas, as práticas educativas, e em especial, em educação patrimonial, foram destaque, durante todo o período de análise, apenas em quatro momentos:

- O Projeto Tudo de Cor para Rio Pardo, de iniciativa de uma empresa fabricante de tintas, prevê a pintura de 19 prédios históricos e da Igreja Matriz, através da doação de tintas pela empresa, e mão-deobra pela comunidade;

\footnotetext{
9 Edição de 23 de outubro de 2012, Secção Panorama Regional, pág $12 . \quad$ Disponível em: <http://www.grupogaz.com.br/gazetadosul/index/edicao:201210-23.html>.
}

- A exposição fotográfica "Rio Pardo: a visão da história pelos jovens", com mais de 80 imagens sobre os principais pontos históricos e turísticos do município, realizada por alunos de uma escola da rede pública estadual da cidade;

- A prática do Núcleo Municipal de Educação de Jovens e Adultos que proporcionou aos seus alunos uma aula prática de história, com visitação aos locais de maior destaque histórico do município;

- A inauguração do Cineclube Cultura Jorge Comassetto, espaço para abrigar até 100 pessoas e infraestrutura para exibir longas, curtas, documentários e animações, dentro do Centro Regional de Cultura de Rio Pardo;

\section{Lembranças esquecidas ou esquecidas lembranças}

O escritor e biólogo moçambicano Mia Couto professa que "o importante não é a casa onde moramos. Mas onde, em nós, a casa mora" ${ }^{10} \mathrm{e}$, portanto, considera-se que um binômio inseparável é a salvaguarda e a degradação, como apresenta Chagas (1996, p. 180) "preservação e deterioração, da mesma forma que memória e esquecimento, são conceitos indissociáveis. [...] Ao estabelecer o que se deve ser preservado - já que é impossível preservar tudo - alguma coisa é lançada no campo da deterioração".

Desta forma, no momento em que uma sociedade constrói a idealização sobre quais são os seus valores culturais, o patrimônio servirá, para fins de sua identificação coletiva, "veiculando uma consciência e um sentimento de grupo, para os próprios e para os demais, erigindo, nesse processo, fronteiras diferenciadoras que permitem manter $e$ preservar a identidade coletiva". (COSTA, REMEDI, 2013, p. 49)

O patrimônio histórico-cultural de uma sociedade, conforme Castro (2007, p. 22) "constituise em um recurso, [...], uma vez que a comunidade concorde com isso, pois não só o passado é

\footnotetext{
10 Mia Couto, in "Um Rio Chamado Tempo, Uma Casa Chamada Terra".
} 
recuperado, como também são revitalizadas todas as atividades e expressões que se possam converter num instrumento a serviço do fortalecimento da identidade da comunidade" e, ao assim considerar-se, "um prédio não será alvo de atos de vandalismo se a pessoa conhecer seu significado e sua história. A pessoa saberá o que ele representa para sua comunidade e para sua história como cidadão." (BARRETO apud Garcia, 2011, p. 51)

Fundamental, portanto, ao evocarmos a salvaguarda de bens materiais - enquanto suporte de memórias individuais e/ou coletivas, é lembrar que, conforme Halbwaches apud Costa, Remedi (2013, p. 34) "a lembrança é em larga medida, uma reconstrução do passado com a ajuda de dados emprestados do presente, e, além disso, preparada por outras reconstruções feitas em épocas anteriores e de onde a imagem de outrora se manifestou já bem alterada" e, como complementa Menezes (1998, p. 92) "à integridade física do artefato corresponde a sua verdade objetiva. Os discursos sobre o artefato é que podem ser falsos".

Paulatinamente há de considerar-se também que "simultaneamente, a ideologia inerente ao modernismo, de fazer tábua rasa do passado para construir um mundo inteiramente novo, rompeu com a linha de continuidade histórica. [...] A conseqüência, como sabemos, é a descontinuidade no tecido das velhas cidades, quando não a sua destruição." (CAMPELLO apud Costa, 2006, p. 25)

Recorrendo-se para tanto, as constatações que a mídia - em especial a mídia impressa regional ${ }^{11}$, a partir de sua finalidade básica de buscar com precisão o direito à informação, divulgando assuntos cujo enfoque em particular (sejam significativos para a formação da opinião pública), encontrou-se, referenciados ao patrimônio cultural material da cidade de Rio Pardo, uma dicotomia de ações que por hora referenciam um processo dialógico entre os diversos atores sociais do

\footnotetext{
${ }^{11}$ Nesta análise, representada pelo diário Jornal Gazeta do Sul, propriedade da Gazeta do Sul S. A. de Santa Cruz do Sul, fundada em 26 de janeiro de 1945, filiada a Associação dos Diários do Interior do Rio Grande do Sul e, distribuída diariamente aos 15 municípios que compõe o Vale do Rio Pardo, além de diversos outros municípios do interior e a capital do estado.
}

município/região/estado que, em consonância buscam a salvaguarda e preservação deste, por hora denuncia o total descaso e negligência com a referida proteção, remontando-nos a proposição de Almeida e Bastos, apud Dias (2009, p. 142) que "há muito a ser feito se realmente quisermos que a preservação se torne uma prática permanente, ainda precisamos transformá-la em sinônimo de desenvolvimento econômico do município, associando ainda mais ao planejamento urbano e à preservação patrimonial."

\section{Referências}

AVÉ-LALLEMANT, Robert. Viagem pela província do Rio Grande do Sul. Belo Horizonte: Itatiaia, 1980. $166 \mathrm{p}$.

CASTRO, Claudiana Y. As representações sociais sobre o patrimônio histórico-cultural e a folheteria turística de Rio Pardo (RS): Um Estudo Exploratório. 137f. Dissertação (Mestrado em Turismo) - Programa de Mestrado em Turismo, Universidade de Caxias do Sul, Caxias do Sul, 2007.

CHAGAS, Mário de S. Memória e poder: dois movimentos. Cadernos de Sociomusologia, no- 19. Centro de Estudos de Sociomuseologia. Lisboa: Universidade Lusófona de Humanidades e Tecnologias, 2002. p. 35-67.

CHAGAS, Mário de S. O museu-casa como problema: comunicação e educação em processo. Rio de Janeiro: Fundação Casa de Rui Barbosa, 1996. p. 177-199.

COSTA, Adriana Schwindt. Patrimônio histórico e cultural em territórios urbanos: um estudo acerca do conjunto edificado da área central da cidade de Rio Pardo (RS). 2006. 202f. Dissertação (Mestrado em Desenvolvimento Regional) - Programa de PósGraduação em Desenvolvimento Regional, Universidade de Santa Cruz do Sul, Santa Cruz do Sul, 2006

COSTA, Heloisa H. F. G. da. Museologia e patrimônio nas cidades contemporâneas: uma tese sobre gestão de cidades sob a ótica da preservação da cultura e da memória. Boletim do Museu Paraense Emilio Goeldi. Ciências Humanas, v7, nำ1, p. 87-101, jan-abr. 2012.

COSTA, M. A. S; REMEDI, J. M. R. Em nome dos valiosos testemunhos de nossas caras tradições: a "invenção" da cidade monumento e a polêmica patrimonialização da Rua da Ladeira - Rio Pardo (RS). Patrimônio e Memória, São Paulo, Unesp, v. 9, n. 1, p. 31-55, jan-jun, 2013. 
DIAS, Renato Duro. Um olhar jurídico-multidisciplinar sobre a preservação do patrimônio cultural edificado na cidade de Pelotas. 2009. 313f. Dissertação (Mestrado em Memória Social e Patrimônio Cultural) - Instituto de Ciências Humanas, Universidade Federal de Pelotas, Pelotas, 2009.

FRANZEN, Beatriz Vasconcelos. Açorianos no Rio Grande do Sul: a identidade açoriana na obra de cronistas, viajantes e historiadores sul-riograndenses.

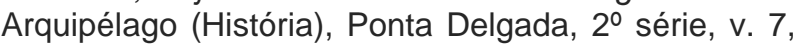
p. 123-142, 2003.

FLORES, Moacyr. História do Rio Grande do Sul. 9. ed. Porto Alegre: Martins Livreiro-Editora, 2013. 208p.

GARCIA, Taís da Silva. A Cultura portuguesa em Rio Pardo, Rio Grande do Sul: referência para a construção da imagem turística da cidade. Mouseion, Canoas, n. 10, jul-dez, p. 48-70, 2011.

GRAEBIN, Cleusa Maria Gomes. Festas de origem açoriana no Rio Grande do Sul. In: XXIV Simpósio Nacional de História, 2007, São Leopoldo. Anais XXIV Simpósio nacional de História. São Leopoldo: ANPUH/Unissinos, 2007. v. 1. p. 1-10.

LOPES, Lélia Coelho. Mulheres chefes de família num contexto beligerante: atuações femininas durante os conflitos fronteiriços na banda oriental (Rio Pardo 1811 a 1828). 2014. 127 f. Dissertação (Mestrado em História) - Programa de Pós-Graduação em História, Universidade Federal de Santa Maria, Santa Maria, 2014.

LOUZADO, E., COSTA, H.. Seleção cultural: (re)pensando o Museo Casa Isleña de San Andres / Colômbia a partir de suas peças, coleções e objetivos. Políticas Culturais em Revista, América do Norte, 8, jun. 2015. Disponível em:http://www.portalseer.ufba.br/index.php/pculturais/ article/view/13744/9756. Acesso em: 28 Jul. 2015.

MENEZES, Ulpiano Toledo Bezerra de. Memória e Cultura Material: documentos pessoais no espaço público. Estudos Históricos, Rio de Janeiro: FGV, n-21, p. 89-102, 1998

REZENDE, Marina de Quadros. Rio Pardo: história, recordações, lendas. 3ำed, 1993 [S.L.:S.n.]. 111 p.

SAINT-HILAIRE, Auguste de. Viagem ao Rio Grande do Sul. $2^{\circ}$ Ed. Tradução de Adroaldo de Mesquita Costa. Porto Alegre: Martins Livreiro Editor, 1987. $496 p$.

VOGT, Olgário Paulo; ROMERO, Maria Rosilane Zoch (Org). Uma luz para a história do Rio Grande: Rio Pardo 200 anos: cultura, arte e memória. Santa Cruz do Sul: Editora Gazeta Santa Cruz, 2010. 208p.

VOGT, O. P; SILVA, A. L; BERTÓ, S. F. F. Rio Pardo: Ascensão e estagnação da Tranqueira Invicta. Ágora, Santa Cruz do Sul, v.2, n.1, p. 53-65, 1996. 